\title{
APPLICATION OF XRM FRAMEWORK FOR DigitALIZATION OF WORKPLACE
}

\author{
Zeljko Stojkic \& Igor Bosnjak
}
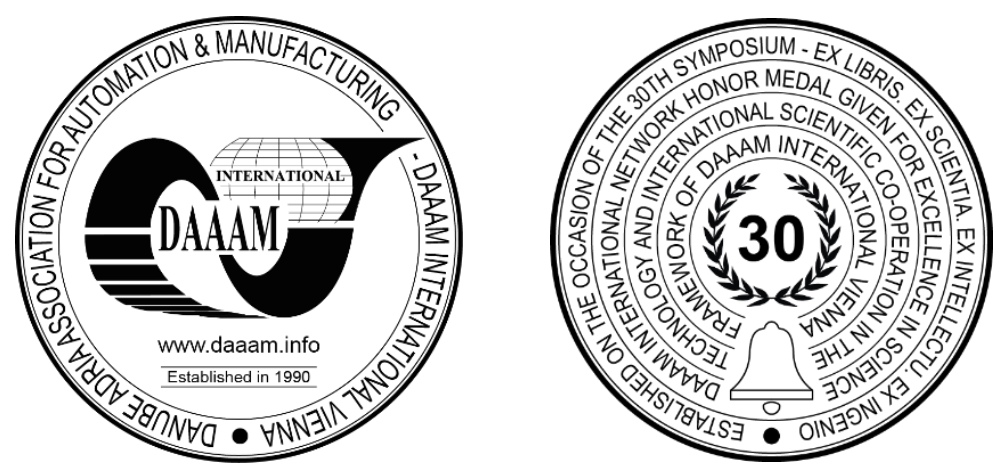

This Publication has to be referred as: Stojkic, Z[eljko] \& Bosnjak, I[gor] (2020). Application of xRM Framework for Digitalization of Workplace, Proceedings of the 31st DAAAM International Symposium, pp.0299-0303, B. Katalinic (Ed.), Published by DAAAM International, ISBN 978-3-902734-29-7, ISSN 1726-9679, Vienna, Austria

DOI: $10.2507 / 31$ st.daaam.proceedings.041

\begin{abstract}
Industry is currently undergoing a transformation towards digitalization and intelligentization of manufacturing processes. To make today's industrial users and students familiar with the topic and the related challenges, a new approach in education is necessary. Beside Industry 4.0 as a production philosophy, lean management that sets out principles and practices of reducing costs through elimination of waste needs to be introduced and enhanced. Moving the Customer Relationship Management (CRM) towards Anything Relationship Management (xRM) leads to a large demystification of CRM process so that it stops being an island which aggregates data from other systems and becomes an integral part of everyday processes. xRM is a proposed platform that may help overcome transformation challenges. This paper presents a FSRE Learning Factory concept of a shop floor workplace digitalization using xRM framework.
\end{abstract}

Keywords: Industry 4.0; xRM; Lean Management; Learning Factory.

\section{Introduction}

The industrialised world is facing a fourth revolution through the realisation of digitalized manufacturing. This revolution, commonly triggered by the German initiative "Industrie 4.0" [1], builds upon computer science; information and communication technologies; and manufacturing science and technology to develop future manufacturing systems with three main characteristics: intelligent information acquisition; connectivity between system elements; and responsiveness to internal and external changes [2]. The concept of Industry 4.0 represents a development that is alternating traditional industries [3]. To make today's industrial users and students familiar with the topic and the related challenges, a new education approach is necessary. The interdisciplinary and holistic approach required by the Industry 4.0 scenario cannot be learned through classical lectures and internships [4]. Customer Relationship Management (CRM) is an old business concept that is becoming popular again because of the new phenomenon of CRM without explicit emphasis on the client or customer. That new phenomenon is called xRM where xRM acronym represents the management of any type of relationship [5].

The aim of this paper is to present a concept of workplace digitalization in FSRE Learning Factory shop floor using $\mathrm{xRM}$ framework and other connected services of data management. Lean management, as a production philosophy that sets out principles and practices of reducing costs through elimination of waste and through simplification of all manufacturing and support systems, will be enhanced by this concept. 
In the second chapter, the idea of digitalization in the context of a Learning Factory will be presented. The third chapter gives introduction to xRM philosophy. Thereafter, the case in FSRE Learning Factory will be presented. A discussion followed by future research and final conclusion is given in the last chapter.

\section{Digitalization in Learning Factories}

For the future of production both academics and practitioners envision significant efficiency gains mainly through consequent digital integration and intelligentization [6] of manufacturing processes [6], [7]. All companies, especially small and medium sized enterprises (SMEs), have the difficulty of having to be highly skilled in applications and technologies of Industry 4.0. This is caused by the fact that those companies usually do not have the manpower to look ahead and beyond their own product and production range to enter new areas and they usually do not have the possibility to invest in emerging technologies as an early adaptor in order not to lose money by focusing on the wrong technologies [4]. Learning factories have proven to be an essential means for educating students and professionals regarding the practical application of production management principles. Lean management as a learning topic has clearly dominated the scene in the last decades. However, for future production scenarios in the sense of Industry 4.0 other competencies also need to be addressed that enable future factory managers and workers to deal with the challenges of an increasingly digitalized production system [7], [8].

In Learning Factories, different approaches for learning are developed. Some of the Learning Factories develop some specific competencies (personal competencies, social/interpersonal competencies, action-related competencies, domainrelated competencies [8]) while others have scenario-based Learning Factory approach. They use structured descriptions of real-world problems and related instructions, to support active learning. Scenarios are therefore the starting point for students to immerse in a real-world problem and a subsequent solution finding process [8]. In this paper, the aim of the concept is to develop a case for domain-related competencies. In the Learning Factory, xRM will be implemented to simulate real industrial environment, where it can be tested in almost the same conditions as it would be used in a real factory. Firstly, the pilot case will be developed at FSRE Learning Factory, and after it is fully implemented, the specific knowledge will be transferred to interested stakeholders (both academics and practitioners). Since xRM requires specific equipment, people and environment where it can be applied, the learning approach of Learning Factories is the most preferable option.

\section{Anything Relationship Management - xRM}

xRM builds upon the basic logic of Relationships Management solutions and the focus is on profitable long-term relations with existing customers [9]. Since its introduction in the early 1980s, the theoretical concept of relationship marketing has been further developed and increasingly supported by software solutions. By the end of the 1990s, these solutions were rebranded as "Customer Relationship Management" (CRM) [10]. CRM systems put the emphasis on the customer side and experienced a period of high popularity growth around the transition of the millennium [11]. CRM was designed to mainly deal with conventional cross-enterprise relationships between two parties, typically between one buyer and one seller organization (1:1 relations). Thus, the complexity of relationships and the diversity of relationship entities covered can be characterized as rather low. In the very beginning, parallel to the rise of CRM, several companies promoted a concept of management of a broader variety of stakeholders [12]. This approach was titled "Extended Relationship Management" (XRM, with a capital "X") and was firstly analysed in detail by Forrester Research in 2001 [12], [13]. Starting around 2005, XRM-labelled systems for different stakeholder groups and different kinds of organizations appeared on the market [12].

The complexity of relationships and the entities involved in relationship structures had started to increase significantly. This trend has continued in the last years. Particularly since 2008, the idea of a holistic and integrated management of all stakeholder relations of an organization has been receiving growing attention [14]. Promoted by Microsoft as "Anything Relationship Management" (xRM, now mostly with a lowercased "x"), this new concept attempts to design and optimize complex relationship structures. xRM began to appear in legal departments, purchasing departments, finance, human resources, project offices and various back office processes (Table 1). Moving the CRM towards xRM leads to a large demystification of CRM process so that it stops being an island that aggregates data from other systems and becomes an integral part of everyday processes [5].

By shifting away from a single system towards a customizable platform/app architecture, xRM solutions provide a means with which various relationship-specific application scenarios can be realized. xRM supports the vision of the networked organization in which all levels of relationships involving organizations, human beings, intelligent objects, object service providers, and ubiquitous computing are coordinated, and transparent, interactive, many-to-many relations and processes are created. Future xRM platforms are therefore likely to link both real and virtual entities dynamically with respect to the context, using a variety of applications including Collaborative Network and Cyber-Physical Systems (Fig. 1.) [12]. 


\begin{tabular}{|c|c|c|}
\hline & $\begin{array}{c}\text { C - client } \\
\text { CRM }\end{array}$ & $\begin{array}{c}\text { x - any } \\
\text { xRM }\end{array}$ \\
\hline Usage & Marketing, sales and customer service & Any team \\
\hline Management & Relationship with clients & Any relationship \\
\hline Automation & Marketing, sales and processes of business services & Any significant process \\
\hline Overview & Interactions, activities, tasks and annual history & $\begin{array}{c}\text { Interactions, activities, tasks and } \\
\text { annual history for X }\end{array}$ \\
\hline Provides & Client-oriented analysis & X-oriented analysis \\
\hline $\begin{array}{c}\text { Integration } \\
\text { with }\end{array}$ & ERP applications & ERP and CRM application \\
\hline
\end{tabular}

Table 1. Comparison of CRM and XRM [5]

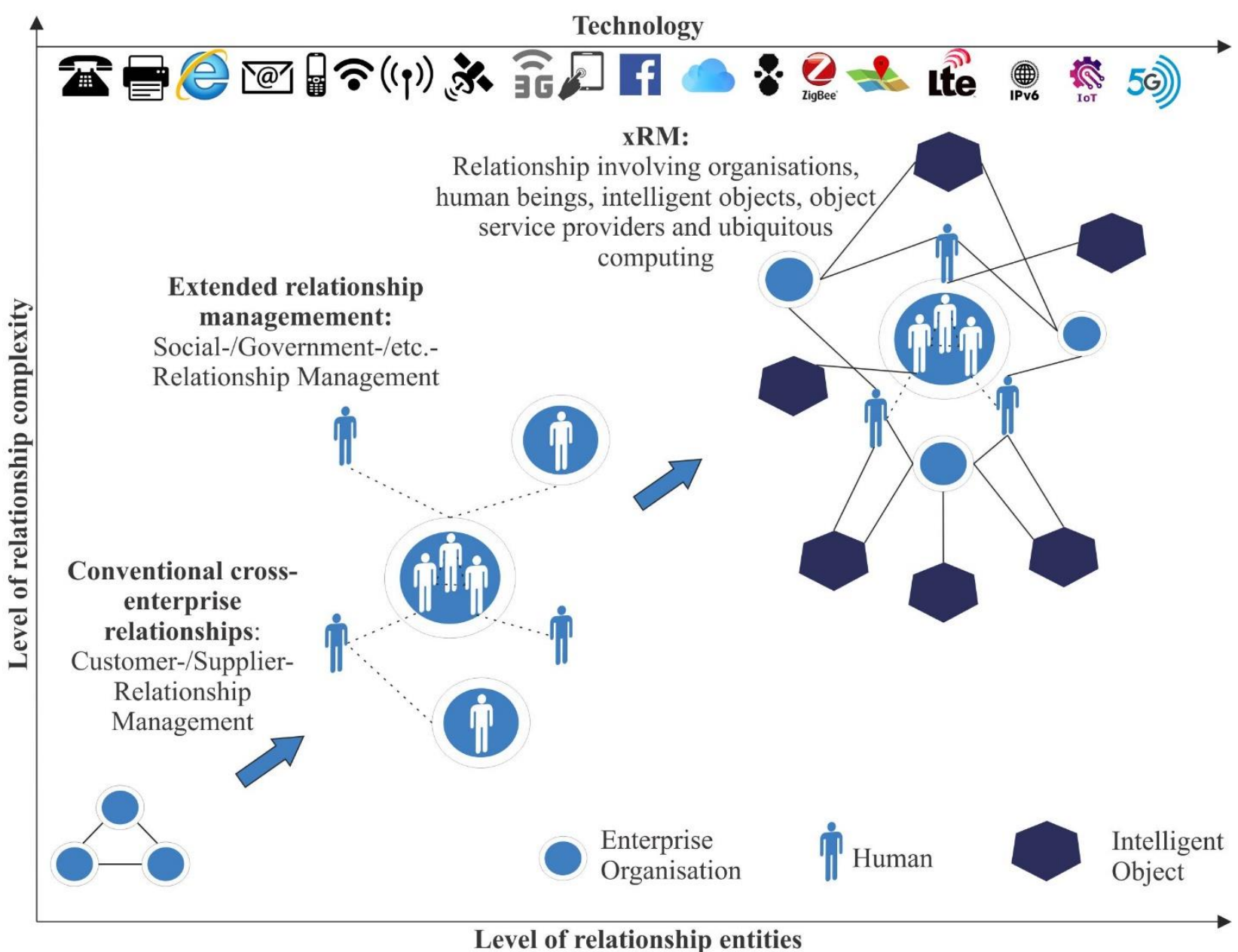

Fig. 1. Evolutionary steps of relationship management, adapted from [13].

\section{Application of xRM framework for digitalization of workplace}

As already mentioned in the previous chapter, relationship management is being used for many purposes, beside traditional CRM process. As relationship management has developed, the Faculty has followed its development and used the new paradigm of CRM, xRM, for different areas of work. It is used in different processes regarding employees and students (digitalization of student enrolment, surveys, etc.). Also, it is used in the faculty's library for book administration, management of classes, as document management system, for generating different reports regarding employees, students, etc. Since the Faculty has established a Learning Factory, the next move is to use an existing xRM system in it. Figure 2 represents the architecture for digitalization of workplaces in the Learning Factory. This approach was developed based on the feedback from the surrounding companies, which are the primary target groups. They have a lack of employees with knowledge of information systems, manufacturing and economics, but understand the needs of integration of different data in one place and education of employees for using an appropriate integration system. 
The Faculty, with its employees and Learning Factory infrastructure has all the necessary parts for xRM development, implementation and education. A requirement regarding this concept is that it needs to be integrated with any other information system or data source. As represented in Figure 2., the database of xRM is the central database. xRM application, through REST/SOAP services, gets and sends data from other information system's databases. xRM enables integration with other different information systems through Open SYNC tools for database integration (ERP system, other data from different sources, sensors, etc.) in one place, which ensures combinations of all data in one place. Every application (assistance system) is customized for different workplaces and only shows necessary data for a specific workplace. Applications can be developed and implemented in three different ways: application development in custom (native) technology, application development and customizing in given xRM framework methodology, and combined development, using both custom and xRM framework methodology. This concept enhances the application of lean manufacturing tools.

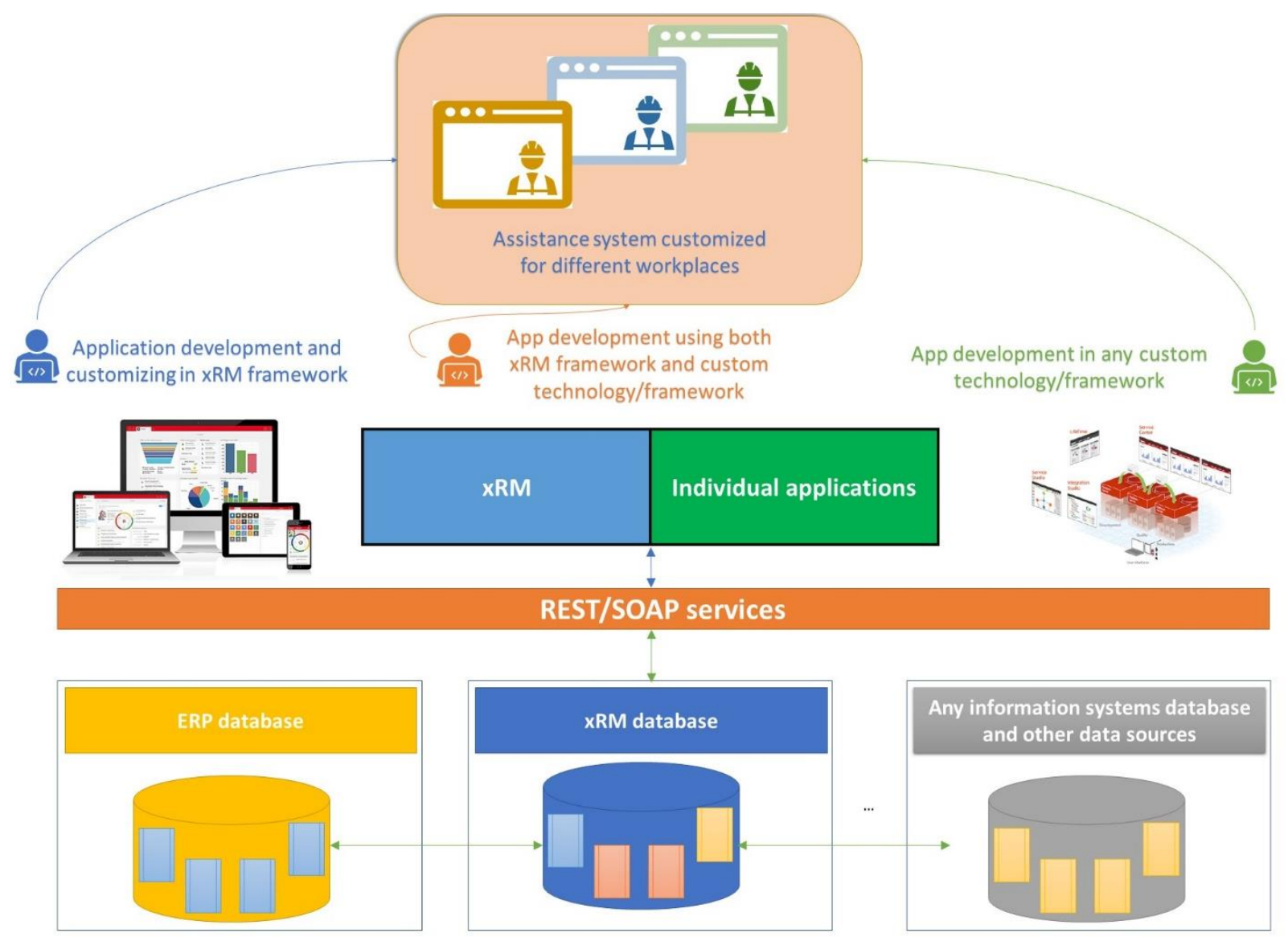

Fig. 2. Application of xRM for digitalization of workplaces - architecture.

Many papers [14], [15], [16], [17] already investigated and proved the hypothesis that Industry 4.0 supports lean manufacturing through lean elements: Supplier feedback, JIT delivery, Pull production, Continuous Flow, Setup time reduction, Total productive maintenance, Statistical process control, Employee involvement etc. Regarding FSRE Learning Factory, digitalization of workplaces would improve supplier feedback through better communication mechanisms and synchronization of data. JIT delivery by suppliers would be enabled by item tagging and wireless tracking of goods. Using standardized interfaces would help in supplier development. Pull production would be enabled by schedule tracking. Real-time inventory tracking, decentralized decision making would ensure continuous flow.

The concept was developed and tested in cooperation with experts from software development, information system modelling and with companies where it should be implemented. The quality of the concept will be tested after its development and implementation within the Learning Factory infrastructure, and after that with different partners from the industry.

\section{Conclusion}

The trend of Industry 4.0 requests companies to adopt to ever-changing conditions. Companies, especially SMEs, have difficulties in achieving Industry 4.0 skills. In the last few years, xRM has developed to a level where it can be used to connect both real and virtual entities. In that way, it became an appropriate framework in development of different solutions for Industry 4.0 cases and transferring the obtained knowledge and experience to stakeholders. 
In this paper, a solution using xRM framework for digitalization of workplaces in a manufacturing shop floor was presented. It is a framework for collection and integration of all the necessary data in one place. It ensures "feeding" workers in workplaces only with the data necessary for their tasks.

In this part of the research we have been mainly dealing with technological solutions that will allow integrated access to a large number of different data through the same platform. In the next steps, we also want to analyse the necessary data for manufacturing (manual assembly, machine-human, robot, robot-human) tasks. The plan is to apply artificial intelligence decision making algorithms. Future steps will be focused on the implementation of the framework in FSRE Learning Factory, and the development of relevant courses, cases and documentation. After that, knowledge and experience that was obtained during the implementation phase would be transferred in both academic and business world.

\section{References}

[1] Kagermann, H., Wahlster, W., \& Helbig, J. (2013). Recommendations for implementing the strategic initiative Industrie 4.0: Final report of the Industrie 4.0 Working Group. Forschungsunion: Berlin, Germany.

[2] Monostori, L., Kádár, B., Bauernhansl, T., Kondoh, S., Kumara, S., Reinhart, G., ... Ueda, K. (2016). Cyberphysical systems in manufacturing. CIRP Annals, 65(2), 621-641. https://doi.org/10.1016/j.cirp.2016.06.005

[3] Mikulić, I., \& Štefanić, A. (2018). The Adoption of Modern Technology Specific to Industry 4.0 by Human Factor. In Proceedings of the 29th DAAAM International Symposium (pp. 0941-0946). Vienna: DAAAM International. https://doi.org/10.2507/29th.daaam.proceedings.135

[4] Faller, C., \& Feldmúller, D. (2015). Industry 4.0 learning factory for regional SMEs. In Procedia CIRP (Vol. 32, pp. 88-91). Elsevier B.V. https://doi.org/10.1016/j.procir.2015.02.117

[5] Stojkic, Z., Majstorovic, V., Visekruna, V., \& Zelenika, D. (2014). Application of lean tools and xrm software solutions in order to increase the efficiency of business processes. In Procedia Engineering (Vol. 69, pp. 41-48). Elsevier Ltd. https://doi.org/10.1016/j.proeng.2014.02.201

[6] Zhou, J. (2013). Digitalization and intelligentization of manufacturing industry. Advances in Manufacturing, 1(1), 1-7. https://doi.org/10.1007/s40436-013-0006-5

[7] Lanza, G., Haefner, B., \& Kraemer, A. (2015). Optimization of selective assembly and adaptive manufacturing by means of cyber-physical system based matching. CIRP Annals - Manufacturing Technology, 64(1), $399-402$. https://doi.org/10.1016/j.cirp.2015.04.123

[8] Erol, S., Jäger, A., Hold, P., Ott, K., \& Sihn, W. (2016). Tangible Industry 4.0: A Scenario-Based Approach to Learning for the Future of Production. In Procedia CIRP (Vol. 54, pp. 13-18). Elsevier B.V. https://doi.org/10.1016/j.procir.2016.03.162

[9] Berry, L. L., \& others. (1983). Relationship marketing. Emerging perspectives on services marketing, 66(3), 33-47.

[10] Buttle, F. (2012). Customer Relationship Management. Concepts and Tools. Elsevier Butterworth-Heinemann. https://doi.org/10.4018/978-1-4666-2524-2.ch008

[11] Fochler, K. (2001). Die DV-technologische Integration der Kundenschnittstelle im Unternehmen. In Customer Relationship Management (pp. 139-169). Springer Berlin Heidelberg. https://doi.org/10.1007/978-3-642-56552$6 \_7$

[12] Britsch, J., Bulander, R., \& Kölmel, B. (2013). Anything Relationship Management (xRM) as management layer for the hyper-connected society. IFIP Advances in Information and Communication Technology, 408, 451-458. https://doi.org/10.1007/978-3-642-40543-3_48

[13] Gummesson, E. (2005). Qualitative research in marketing: Road-map for a wilderness of complexityand unpredictability. European Journal of Marketing. https://doi.org/10.1108/03090560510581791

[14] Karre, H., Hammer, M., Kleindienst, M., \& Ramsauer, C. (2017). Transition towards an Industry 4.0 State of the LeanLab at Graz University of Technology. Procedia Manufacturing, 9, $206-213$. https://doi.org/10.1016/j.promfg.2017.04.006

[15] Sanders, A., Elangeswaran, C., \& Wulfsberg, J. (2016). Industry 4.0 implies lean manufacturing: Research activities in industry 4.0 function as enablers for lean manufacturing. Journal of Industrial Engineering and Management, 9(3), 811. https://doi.org/10.3926/jiem. 1940

[16] Chen, J. C., \& Chen, K. M. (2014). Application of ORFPM system for lean implementation: An industrial case study. International Journal of Advanced Manufacturing Technology, 72(5-8), 839-852. https://doi.org/10.1007/s00170-014-5710-1

[17] Meudt, T., Metternich, J., \& Abele, E. (2017). Value stream mapping 4.0: Holistic examination of value stream and information logistics in production. CIRP Annals - Manufacturing Technology, 66(1), $413-416$. https://doi.org/10.1016/j.cirp.2017.04.005 